\title{
An experimental comparison of sequential first- and second-price auctions with synergies
}

Citation for published version (APA):

Leufkens, K., Peeters, R. J. A. P., \& Vorsatz, M. (2007). An experimental comparison of sequential firstand second-price auctions with synergies. METEOR, Maastricht University School of Business and Economics. METEOR Research Memorandum No. 055 https://doi.org/10.26481/umamet.2007055

Document status and date:

Published: 01/01/2007

DOI:

10.26481/umamet.2007055

Document Version:

Publisher's PDF, also known as Version of record

\section{Please check the document version of this publication:}

- A submitted manuscript is the version of the article upon submission and before peer-review. There can be important differences between the submitted version and the official published version of record.

People interested in the research are advised to contact the author for the final version of the publication, or visit the DOI to the publisher's website.

- The final author version and the galley proof are versions of the publication after peer review.

- The final published version features the final layout of the paper including the volume, issue and page numbers.

Link to publication

\footnotetext{
General rights rights.

- You may freely distribute the URL identifying the publication in the public portal. please follow below link for the End User Agreement:

www.umlib.nl/taverne-license

Take down policy

If you believe that this document breaches copyright please contact us at:

repository@maastrichtuniversity.nl

providing details and we will investigate your claim.
}

Copyright and moral rights for the publications made accessible in the public portal are retained by the authors and/or other copyright owners and it is a condition of accessing publications that users recognise and abide by the legal requirements associated with these

- Users may download and print one copy of any publication from the public portal for the purpose of private study or research.

- You may not further distribute the material or use it for any profit-making activity or commercial gain

If the publication is distributed under the terms of Article $25 \mathrm{fa}$ of the Dutch Copyright Act, indicated by the "Taverne" license above, 
Kasper Leufkens, Ronald Peeters, Marc Vorsatz

An experimental comparison of sequential firstand second-price auctions with synergies

$\mathrm{RM} / 07 / 055$

JEL code: C91, D44

\section{METE@R}

Maastricht research school of Economics of TEchnology and ORganizations

Universiteit Maastricht

Faculty of Economics and Business Administration P.O. Box 616

NL - 6200 MD Maastricht

phone : ++31433883830

fax : :+31433884873 


\title{
An experimental comparison of sequential first- and second-price auctions with synergies*
}

\author{
Kasper Leufkens ${ }^{\ddagger} \quad$ Ronald Peeters ${ }^{\ddagger \S} \quad$ Marc Vorsatz $^{\ddagger}$
}

December 17, 2007

\begin{abstract}
The presence of synergies in recurrent procurement auctions leads to an exposure problem and asymmetries among bidders. We consider sequential first- and second-price auctions with synergies in a setting with four bidders. In a series of experiments we compare the performance of the two pricing formats for three different sizes of the synergy. We find that for small synergies, the first-price auction performs better in terms of efficiency, revenue, and the probability on losses. However, once the synergy factor becomes very large the performance of the two different pricing formats becomes more similar. We also find that even though the potential total surplus that can be divided between buyers and seller increases in the synergy factor, subjects' earnings within a pricing rule do not significantly change in the synergy factor. Finally, we observe that the two pricing formats give rise to different price trends within the auction sequence. In general, our results provide support for the common use of first-price instead of second-price auctions for public procurement.

JEL Classification: C91, D44.
\end{abstract}

Keywords: Asymmetric auction, Experiment, Exposure problem, Sequential auction.

\footnotetext{
${ }^{*}$ We want to thank Arno Riedl, Martin Strobel, and the conference and seminar participants in Kos (SAET 2007), Utrecht (NAKE Research Day 2007), and Maastricht (BEE seminar) for helpful comments and suggestions. Financial support by the Dutch Science Foundation (NWO) is gratefully acknowledged.

${ }^{\ddagger}$ Department of Economics, Maastricht University, P.O. Box 616, 6200 MD Maastricht, The Netherlands.

${ }^{\S}$ Corresponding author, email: R.Peeters@algec.unimaas.nl.
} 


\section{Introduction}

Winning multiple contracts in multi-unit procurement auctions can lead to cost advantages due to synergies. These synergies can be material, for instance owning specialized equipment, or intangible, such as expertise. Hendricks and Porter's (1988) study of drainage lease auctions was the first empirical study to show that interdependencies among the values of objects affect the outcome of a sequential auction. More recent, Ausubel et al. (1997) show that synergies associated with winning multiple adjacent licenses in the United States spectrum auctions affected bidding strategies. Rusco and Walls (1999) and De Silva (2005) find that in, respectively, timber and road construction auctions, spatial correlation of bids induces more aggressive bidding. Cramton (2002) argues that one reason for the enormous revenue in the spectrum auction by the United Kingdom is that it was the first in the sequence of UMTS auctions throughout Europe (see also Van Damme (2002)). Winners in the UK auction were well positioned for subsequent auctions and, hence, bidders could view it as a foot-in-the-door to Europe. Finally, De Silva et al. (2005) show that in road construction auctions, previous winners are more likely to win in subsequent auctions.

Research on multi-object auctions has mainly focussed on objects that are auctioned within a short period of time. The auctions take place either simultaneously or in a sequence immediately after each other. However, a notable characteristic of procurement is its recurrent nature. Construction contracts, military procurement, and service contracts are all examples of this recurrence. In these settings, auctions take place sequentially but with time periods in between. A consequence of the presence of synergies in such settings, is that bidders' valuations are stochastically dependent across auctions. Bidders then face an exposure problem as they can end up winning contracts that are too expensive if complementary contracts are not won. Furthermore, the presence of synergies induces future asymmetries between bidders which makes the bidding environment more complex.

In this paper, we experimentally analyze a sequential auction with synergies with four bidders. Based on the aforementioned sequentiality of procurement auctions, we consider a sequential auction of two stochastically equivalent objects where the valuation of the second object is uncertain during the first auction. The winner of the first auction receives an upgrade for his valuation in the second auction. We compare sequential first- and second-price auctions for a baseline treatment without synergies and for two treatments with positive synergies of different sizes.

The setting analyzed in this paper cannot be solved theoretically for a first-price auction. By comparing the experimental data both within and between the two pricing formats, we gain insights in how bidding behavior is influenced by the presence of an exposure problem and asymmetries between bidders. The responsiveness of the bidding, and the probability of making losses in particular, to the presence and the size of the synergy are important for public policy. 
Theoretical research on sequential auctions with synergies was initiated by Branco (1997), who attributed the empirical observation of declining prices in sequential auctions of homogeneous objects to the presence of synergies. Jeitschko and Wolfstetter (2002) extend this result to a sequential auction of stochastically equivalent objects for both first- and secondprice auctions. Leufkens et al. (2006) analyze not only price trends and revenues, but also the consequences the presence of positive synergies has for bidders. They find that bidders' expected total payoffs from the auction sequence decreases in the synergy factor and that there is a serious probability of making losses. Leufkens and Peeters (2007) compare sequential first- and second-price auctions and conclude that although expected revenue and efficiency are higher in second-price auctions, first-price auctions may be preferred based on a less severe exposure problem.

Theoretical research on sequential auctions with synergies is seriously restricted by the absence of an explicit mathematical formula for the equilibrium bidding functions in an asymmetric first-price auction with more than two bidders. Jeitschko and Wolfstetter (2002) and Leufkens and Peeters (2007) compare sequential first- and second-price auctions with synergies, but both are restricted to a setting with two bidders. For more than two bidders, it is not clear how the two pricing formats will perform.

Experimental research on multi-object auctions was spurred by the spectrum auctions, for which guidance on the auction rules was needed. Few experimental analyses on the exposure problem in sequential auctions have been conducted. Février et al. (2007) analyze sequential auctions of two identical objects with a buyer's option, which means that the winner of the first object has the option to buy the second object at the winning price. They consider a setting in which the valuation for the second object increases if the first is won, and compare the revenue and usage of the buyer's option in the four main auction institutions. They note that subjects bid too conservatively compared to theory which can be attributed to the presence of the exposure problem.

In our setting, the upgrade for the valuation of the winner of the first auction makes the second auction asymmetric. Güth et al. (2005) experimentally analyze asymmetric firstand second-price auctions with two bidders in which the role of strong and weak bidder are assigned exogenously and remain fixed. They find that in first-price auctions a weak bidder bids more aggressively than a strong bidder. Furthermore, they test bidders' preference for first- versus second-price auctions and find that a strong bidder is willing to pay more than a weak bidder to dictate the auction rule.

Grimm et al. (2006) consider an asymmetric setting comparable to Güth et al. (2005). They randomly select one of the two bidders prior to an auction and give him an investment opportunity to become the strong bidder. When the investment opportunity is given, the auction valuation is not known yet. They find that bidders invest more often prior to secondprice auctions than to first-price auctions. However, by not having a competition for the possibility and the cost at which one can become the strong bidder, their setting differs 
fundamentally from ours.

We find that the aggressiveness of bidding in the first auction increases in the synergy factor. For small synergies, the first-price auction performs better in terms of efficiency, revenue, and the probability on losses. However, once the synergy factor becomes very large the performance of the two different pricing formats becomes more similar, although the first-price auction never performs worse than the second-price auction on all three aspects. Although we observe differences in bid shading between strong and weak bidders in asymmetric firstprice auctions, this difference is too small to cause significant inefficiencies. The average first auction payoff decreases in the synergy factor and is negative for large synergies. Furthermore, we observe that even though the potential total surplus that can be divided between buyers and seller increases in the synergy factor, subjects' earnings within a pricing rule do not significantly change in the synergy factor. Finally, we find that the two pricing formats give rise to different price trends within the auction sequence.

The remainder of this paper is organized as follows. In Section 2, we discuss the setting and theoretical insights. In Section 3, we describe the experimental design, and the laboratory procedures. The analysis of the data is presented in Section 4. The conclusion can be found in Section 5. Appendix A contains the instructions and control questions for the subjects.

\section{Model}

We consider a private value auction of two stochastically equivalent objects. The objects are auctioned sequentially under identical auction rules, and the same four bidders participate in both auctions. Valuations are individually uncorrelated and drawn independently according to a uniform distribution between 0 and 100. Furthermore, the valuation for the second object is not yet known during the first auction.

If the first auction is won, the drawn second auction valuation will be multiplied with a synergy factor $s \geq 1$. That is, if bidder $i$ wins the first object, his valuation in the second auction (weakly) increases from $v_{2 i}$ to $s v_{2 i}$. Since the second auction valuation is not yet known during the first auction, winning the first auction leads to an increase in the expected valuation for the second object. After each auction, bidders are instantly informed whether or not they won the object, the price at which the object was sold, and their payoff, which is the difference between the valuation and the price in case the auction is won and zero otherwise.

The present setting represents a recurring auction like the annual auctioning of contracts for public services. The exact details of future contracts are not yet specified and, therefore, contracts are considered as a priori identical. The benefits from synergies are only attributed to the second object as the result of the order in which projects are executed. For instance, expertise is created during the first project and this gives benefits for the second, or specialized equipment is needed which then does not need to be acquired for a possible second project. The way in which synergies are modeled ensures that there is an observable relationship 
between the benefits from synergies and the intrinsic value of the second object. The actual gain due to synergies depends on the combination of the synergy factor $s$ and the initial valuation for the second object. Our setting can find its application in many procurement situations and in spectrum auctions where bidders benefit from a win in one area in the creation of a domain consisting of multiple contiguous areas.

Before we discuss the theoretical insights, we need to introduce some notation. We write $b_{k i}$ and $v_{k i}$ for respectively the bid and valuation in auction $k$ of bidder $i$. With $\bar{\pi}_{k i}$ we denote the expected instantaneous payoff of auction $k$ for bidder $i$ prior to the realization of the valuations for this auction and, for $k=2$, given the history of the previous auction. The expected price of auction $k, \bar{p}_{k}$, is also prior to the realization of the valuations and thus the seller's expected revenue of that auction. In the second auction, bidder $w$ and bidder $\ell$ are a bidder $i$ that, respectively, won or lost the first auction.

The equilibrium bidding strategies for a sequential second-price auction can be found by applying backwards induction. The symmetric equilibrium for four risk-neutral bidders is given by:

$$
\begin{aligned}
& b_{1 i}^{*}=v_{1 i}+\left(50 s-75+25 \frac{1}{s}\right) \quad \bar{\pi}_{1 i}=5-\frac{1}{4}\left(50 s-75+25 \frac{1}{s}\right) \\
& b_{2 i}^{*}=\left\{\begin{array}{ll}
v_{2 i} & \text { if auction } 1 \text { is lost } \\
s v_{2 i} & \text { if auction } 1 \text { is won }
\end{array} \quad \bar{\pi}_{2 i}= \begin{cases}5 \frac{1}{s} & \text { if auction } 1 \text { is lost } \\
50 s-75+30 \frac{1}{s} & \text { if auction } 1 \text { is won }\end{cases} \right. \\
& \bar{p}_{1}=60+\left(50 s-75+25 \frac{1}{s}\right) \quad \bar{p}_{2}=75-15 \frac{1}{s}
\end{aligned}
$$

The intuition for the equilibrium bidding strategies is straightforward. The second auction is an one-shot asymmetric second-price auction, in which truthful bidding is (weakly) dominant. When positive synergies are present, the expected instantaneous payoff of the second auction is larger if the first auction is won than if the first auction is lost. The actual value of winning the first auction is then not only the value of the first object, but also the difference in the expected instantaneous payoff of the second auction between winning and losing the first auction. For the remainder of this paper we refer to this difference in the expected instantaneous second auction payoff as the option value. It then immediately follows that bidding the valuation plus the option value forms a (weakly) dominant strategy in the first auction. Notice that the option value, and hence the first auction bidding, increases in the synergy factor.

For a first-price auction, the present setting cannot be solved analytically for its equilibrium when there are more than two bidders. This is due to the absence of an explicit mathematical formula for the equilibrium bidding functions in the asymmetric auction of the second object. Consequently, we provide a discussion on the qualitative impact the presence of positive synergies is expected to have on the bidding in the sequential first-price auction.

Winning the first auction leads to an increase in the expected valuation for the second object. Therefore, suppose that the expected instantaneous second auction payoff of the winner of the first auction increases in the synergy factor and decreases for the loser of the 
first auction. ${ }^{1}$ The option value is then positive and increases in the synergy factor. In the first auction, bidders not only bid for the object but also for the option value. This shifts the supports of the distribution up by the option value, and, consequently, in equilibrium all bidders add the option value to the bid they would make in a one-shot auction (assuming risk-neutrality).

Based on the equilibrium bidding strategies for the second-price auction and the suppositions for the first-price auction, we conclude that the bidding behavior in the first auction increases in the synergy factor in both pricing formats. In a second-price auction, bidders bid above their valuation as soon as $s>1$, which can lead to an instantaneous loss when the first object is won. In a first-price auction, bidders bid above their valuation if the synergy factor is sufficiently large to offset the bid-shading. Then, winning the auction always results in an instantaneous loss. The valuation of the second object is uncertain during the first auction. Bidders face an exposure problem, since a (possible) instantaneous loss in the first auction might not be recovered during the second auction.

In the first auction, a bidder bids the same as in a one-shot auction plus the option value. The expected probability of winning the first auction is one fourth. Therefore, the expected instantaneous first auction payoff equals the payoff of an one-shot auction, minus one fourth times the option value. It then follows that the ex-ante expected total payoff of the auction sequence as a whole, equals the expected payoff of an one-shot auction plus the expected instantaneous payoff in the second auction when the first auction has been lost:

$$
\bar{\mu}_{i}=\bar{\pi}_{1 i}+\frac{1}{4} \bar{\pi}_{2 w}+\frac{3}{4} \bar{\pi}_{2 \ell}=\bar{\pi}-\frac{1}{4}\left(\bar{\pi}_{2 w}-\bar{\pi}_{2 \ell}\right)+\frac{1}{4} \bar{\pi}_{2 w}+\frac{3}{4} \bar{\pi}_{2 \ell}=\bar{\pi}+\bar{\pi}_{2 \ell} .
$$

The ex-ante expected total payoff is thus decreasing in the synergy factor for both pricing formats. This means that the larger the possible benefit from synergies becomes, the smaller the expected total payoff of the bidders will be.

It is well known that (part of) a possible rent is dissipated during the competition for that rent. However, in this setting not only the possible rent is completely dissipated, bidders are even worse off than in a setting without synergies. When the synergies are large, bidders have half the ex-ante expected total payoff they would have if there were no synergies. Given the fact that the total surplus that can be divided between the seller and the bidders is larger with than without synergies, this is especially surprising. Instead of benefiting from the presence of synergies bidders suffer from it.

\section{$3 \quad$ Experimental design and procedures}

In order to analyze the impact positive synergies have on a sequential sealed-bid auction of two objects we implemented a $3 \times 2$ between-subjects design, which is depicted in Table 1 . The

\footnotetext{
${ }^{1}$ For an asymmetric first-price auction, this does not necessarily hold for certain special cases with common supports but differences in the cumulative distribution functions of the bidders' valuations (Lebrun, 1998). This is not the case in the present setting, and Table 9 shows that the supposition does hold for our experiment.
} 
dimensions relate to the size of the synergy factor and the pricing rule of the auctions. For both pricing-rules we conducted a baseline treatment without synergies and two treatments with two different positive synergy factors. Subjects were randomly assigned to a group of four bidders. Although it was common knowledge that group composition did not change during the experiment, collusion is not a concern in case of four bidders (see Huck et al. (2004)). All groups played fifty rounds and a round consisted of two sequential auctions. In total, there are ten independent observations per treatment.

\begin{tabular}{lcc}
\hline & First-price & Second-price \\
\hline No synergy & FP1.0 & SP1.0 \\
Synergy factor 1.5 & FP1.5 & SP1.5 \\
Synergy factor 2.0 & FP2.0 & SP2.0 \\
\hline
\end{tabular}

Table 1: The experimental treatments.

In the first auction of each round, the valuation of a bidder was given by 50 plus an independently drawn and individually uncorrelated integer between 0 and 100 . We added a constant of 50 in order to allow for underbidding at all valuations. In each auction, the random component of the valuation and the total valuation were listed below each other on the screen. In the baseline treatments, the procedure in the second auction was identical to that in the first. Hence, subjects played two one-shot auctions per round. In the treatments with positive synergies, the second auction valuations of the losers of the first auction were again determined by 50 plus a randomly drawn integer between 0 and 100. For the winner of the first auction, the second auction valuation was determined by multiplying the randomly drawn integer with the synergy factor and then adding 50 . In the second auction, the winner of the first auction observed both the drawn random component, the upgraded random component and the valuation. Thus, in the first auction of a round bidders' valuations lay between 50 and 150. In the second auction of a round, the valuations of the losers lay between 50 and 150 and the valuation of the winner between 50 and $50+100 \mathrm{~s}$. Via control questions we tested whether subjects understood this composition of their valuation and that their auction payoff would be based on the valuation.

Subjects did not know their second auction valuation during the first auction. In the treatments with synergies, subjects were informed during the first auction of a round that the random component of the second auction valuation would be upgraded by the synergy factor, $s$, if this auction was won. After an auction, each subject received an overview of the auction outcome; the valuation, the bid submitted, whether or not the auction was won, the price at which the object was sold and the payoff from the auction. Subjects never (directly) observed the valuations and bids of others. At the end of each round, subjects also received an update on their total payoff.

To maximize the comparability of the treatments, series of valuations were independently drawn for forty bidders and then used in all treatments with the same group compositions. 
Bidders' valuations were expressed in Experimental Currency Units (ECU). Subjects could submit any bid between 0 and 999 ECU. Bids did not have to be integers. In case of tied highest bids, the winner was randomly selected from these bidders. The experiments were conducted in the experimental laboratory of the faculty of economics and business administration at Maastricht University in March 2007. In total, 240 undergraduate students participated, and sessions lasted approximately 90 minutes. We conducted two sessions of twenty subjects per treatment which resulted in ten independent observations per treatment. The groups were formed randomly and group members were anonymous to each other. Subjects earned ECU during the experiment that were converted into Euros at a known exchange rate at the end of the experiment. Since we only had theoretical predictions for the second-price treatments and the revenue ranking between first- and second-price auctions was ambiguous, we used the same exchange rates in both pricing formats. For the baseline treatments, synergy factor 1.5, and synergy factor 2.0, the exchange rate for 1 ECU were respectively 2.2, 2.4, and 2.4 Eurocents. The average payoff was $€ 11.34$ including an initial endowment of $€ 5$.-. None of the subjects received a negative payoff.

The experiment was announced via email and subjects could register online using their matriculation number. This ensured that students could participate only once. When students arrived at the laboratory, they had to draw a card from a deck that determined at which computer terminal they were placed. In case more than twenty students showed up for a session, we included blank cards in the deck. Students that drew a blank card could not participate and were paid $€ 3$.- as compensation.

All interactions took place via computers that were connected to a network and the computer terminals were placed in such a way that subjects could neither see the screens of others nor make eye contact with them. The experiment was programmed and conducted with the software z-Tree (Fischbacher, 2007). Before the start of a session, subjects read the instructions and were allowed to privately ask questions that were then privately answered. After reading the instructions, subjects had to answer control questions, which tested their understanding of the instructions. ${ }^{2}$ One of the experimenters checked the answers, and the experiment only started after all subjects answered each question correctly. Payment took place privately, and subjects had to leave the laboratory immediately once paid.

\section{Experimental results}

In this section, we discuss the results for efficiency, revenue, and bidders' payoffs. Thereby, we concentrate on the results in the last 25 rounds. The game played is rather complex, and we are interested in mature behavior only. The choice for the last 25 rounds was made upfront. However, the results are found to be robust to adding or dropping a couple of rounds.

\footnotetext{
${ }^{2}$ See Appendix A for the instructions and control questions.
} 


\subsection{Bid functions}

The presence of positive synergies should lead to higher bidding in the first auction of a round. To see whether this is indeed the case, the first auction bid functions are estimated using a generalized least squares random-effect model with valuation as independent variable and a constant. In order to correct for dependency within groups, each group is treated as an independent unit. The estimation results per treatment are reported in Table 2. The estimated bid function, $\hat{\beta}_{0}+\hat{\beta}_{1} v$, can been seen in Figure $1 .^{3}$

\begin{tabular}{llllllr}
\hline Coefficient & FP1.0 & FP1.5 & FP2.0 & SP1.0 & SP1.5 & \multicolumn{1}{c}{ SP2.0 } \\
\hline Constant & $5.85(0.55)$ & $8.07(1.24)$ & $7.80(1.78)$ & $2.05(1.07)$ & $7.51(1.63)$ & $14.04(3.17)$ \\
Valuation & $0.88(0.01)$ & $0.90(0.01)$ & $0.94(0.01)$ & $1.02(0.01)$ & $1.04(0.02)$ & $1.06(0.02)$ \\
\hline
\end{tabular}

Table 2: Estimated parameters of the bid functions with standard errors in brackets.
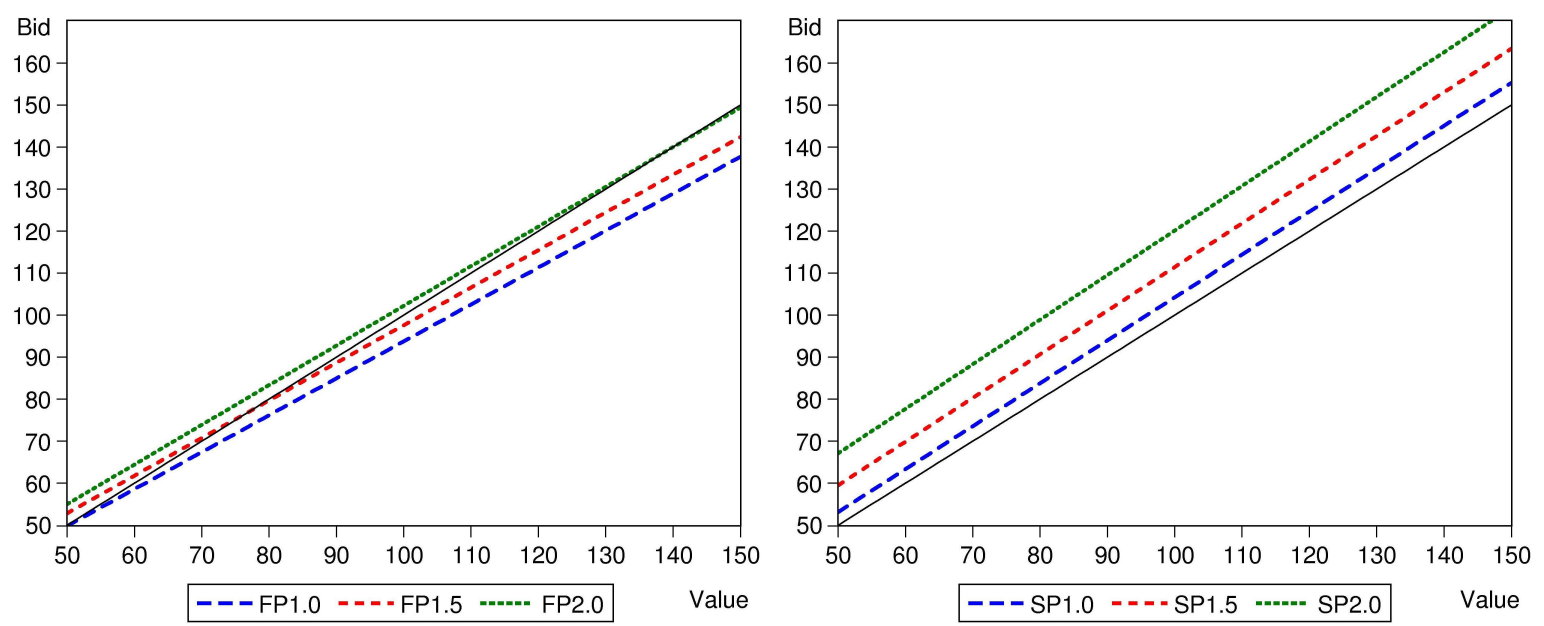

Figure 1: Estimated bid functions.

The estimation results in Table 2 show, that the effect of the synergy factor on the bid function in the first-price auctions is not completely as predicted. The constant is lower in FP2.0 than in FP1.5, and the coefficient of the valuation increases in the synergy factor. Within the second-price treatments, the constant increases in the synergy factor. Still, this increase is well below the theoretical prediction in case of risk neutrality. Furthermore, we observe that the coefficient of the valuation is always above one and increases slightly in the synergy factor.

From Figure 1 we can conclude that, for both price rules, the bidding increases in the synergy factor. Bids equal to valuation are shown by the thin line in the figure. In the firstprice treatments, bids are above valuation in FP2.0 over almost the complete domain, and in FP1.5 for low valuations. In the second-price treatments, bids are always above valuation.

\footnotetext{
${ }^{3}$ Bids that were more than 1.5 times the interquartile range above the third quartile, were omitted from the analysis. For the first-price treatments we also omitted a small number of bids of (almost) zero. The pattern of the estimated bid functions in Figure 1, does not change if we include all observations.
} 


\subsection{Efficiency}

The presence of positive synergies should not affect the efficiency of the first auction of a round. Within a treatment, all bidders should add the same positive constant to the equilibrium bid of an one-shot auction, and, hence, the bidder with the highest valuation still wins. The second auction of a round is an asymmetric auction with four bidders. Bidding truthfully is still a weakly dominant strategy in a second-price auction. However, it has been shown for two bidders that an asymmetric first-price auction is not guaranteed to be efficient (Plum, 1992). The reason is that the bidder that draws from the more favorable valuation distribution shades his bid more at a given valuation than the other bidder.

We measure efficiency by $\left(v_{\text {win }}-50\right) /\left(v_{\max }-50\right)$, where $v_{\text {win }}$ denotes the valuation of the winner of the auction and $v_{\max }$ corresponds to the highest valuation within the group. We subtract the constant for normalization. We also report the relative occurrence of an efficient auction.

\begin{tabular}{lcccccc}
\hline & FP1.0 & SP1.0 & FP1.5 & SP1.5 & FP2.0 & SP2.0 \\
\hline Occurrence & 89.60 & 89.60 & 86.40 & 82.00 & 83.60 & 77.20 \\
Efficiency & 99.10 & 99.07 & 98.65 & 96.65 & 98.02 & 94.67 \\
& $(0.971)$ & $(0.280)$ & $(0.015)$ \\
\hline
\end{tabular}

Table 3: The efficiency and occurrence of an efficient auction in percentages for auction 1. In brackets are the exact two-sided Mann-Whitney statistics, which are based on the average efficiency per group.

In the upper part of Table 3, it can be seen that the results are (almost) the same for the baseline treatments of both pricing-rules. However, for a given positive synergy factor, the first-price auction appears to perform better than the second-price auction. The last row of Table 3 contains the significance levels of a two-sided Mann-Whitney test based on average efficiency per independent observation. The difference is only significant between FP2.0 and SP2.0. Mann-Whitney tests based on the relative occurrence of an efficient auction lead to the similar results.

It can also be seen in Table 3 that, within both the first- and second-price treatments, the efficiency decreases the larger the synergies are. For the first-price treatments, we find by means of two-sided Mann-Whitney tests, that the efficiency in FP1.0 is significantly higher than in FP2.0 $(p=0.024)$, but not than in FP1.5 $(p=0.190)$. Similarly, for the second-price treatments, the efficiency in SP1.0 is significantly higher than in both SP1.5 $(p=0.043)$ and SP2.0 $(p=0.000)$. Comparisons between the efficiency for the two different positive synergy factors within a pricing rule does not lead to any significant result. Thus, for both pricingrules the presence of positive synergies leads to a lower efficiency in the first auction, which conflicts with theory.

In Table 4, the efficiency measures are presented for the second auction in a round. In the upper part of the table, it can be seen that the efficiency and occurrence of an efficient auction are again (almost) the same for the baseline treatments of both pricing-rules. In contrast to 


\begin{tabular}{lcccccc}
\hline & FP1.0 & SP1.0 & FP1.5 & SP1.5 & FP2.0 & SP2.0 \\
\hline Occurrence & 88.80 & 88.80 & 90.80 & 89.20 & 90.00 & 88.40 \\
Efficiency & 98.99 & 99.24 & 99.32 & 98.93 & 98.45 & 97.44 \\
& $(0.739)$ & $(0.342)$ & $(0.247)$ \\
\hline
\end{tabular}

Table 4: The efficiency and occurrence of an efficient auction in percentages for auction 2. In brackets are the exact two-sided Mann-Whitney statistics, which are based on the average efficiency in a group.

expectation, the efficiency in the first-price auction is not lower than that in the second-price auction for a given positive synergy factor. The last row of the table contains the significance levels of a two-sided Mann-Whitney test based on the average efficiency per independent observation. We do not find any significant differences. The results for the second auction in a round are surprising, especially since Güth et al. (2005) found that for two bidders, the efficiency in an asymmetric first-price auction is lower than in a second-price auction.

We cannot compare the efficiency within the first-price (or second-price) treatments with the efficiency measure defined above. The reason is that given there is an inefficiency, the expected efficiency is lower the larger the synergy factor. Consequently, we conduct twosided Mann-Whitney tests on the relative occurrence of an efficient auction per independent observation.

Based on the theory by Plum (1992) for two bidders, we would expect the efficiency in FP1.0 to be significantly higher than in FP1.5 and FP2.0. However, Table 4 shows that the relative occurrence of an efficient auction is higher when positive synergies are present. We cannot conclude that the efficiency in the second auction of FP1.0 is significantly different from $\operatorname{FP} 1.5(p=0.509)$ or FP2.0 $(p=0.896)$.

Within the second-price treatments, there should not be any difference in the efficiency, since truthful bidding is still a weakly dominant strategy. Therefore, we conduct MannWhitney tests based on the relative occurrence of an efficient auction per independent observation. From this we cannot conclude that the efficiency in the second auction of SP1.0 significantly differs from SP1.5 $(p=0.914)$ or SP2.0 $(p=0.977)$.

The theoretical cause of inefficiencies in an asymmetric first-price auction is the difference in the bid shading for the two types of bidders. Güth et al. (2005) indeed observe this in their experiment, and, by applying the same analysis, we will now investigate whether this property also holds in our experiment with four bidders. In Table 5, we compare the median degree of bid shading between the two types of bidders for valuations that lay within the stated intervals. ${ }^{4}$ The degree of bid shading is defined as $(v-b(v)) / v$.

In general, we observe that, for both types of bidders, the median degree of bid shading increases in the valuation. In FP1.5, the winner shades more than the losers when the valuations are in the two upper intervals. In FP2.0, the first auction winner always shades

\footnotetext{
${ }^{4}$ We take the median instead of the average because subjects with low valuations occasionally submitted a bid of zero. Removing these bids and then taking the average leads to the same insights as Table 5.
} 


\begin{tabular}{lcccc}
\hline & \multicolumn{2}{c}{ FP1.5 } & \multicolumn{2}{c}{ FP2.0 } \\
& Losers & Winners & Losers & Winners \\
\hline$v \in[50,75]$ & 0.028 & 0.028 & 0.020 & 0.034 \\
$v \in(75,100]$ & 0.034 & 0.026 & 0.024 & 0.046 \\
$v \in(100,125]$ & 0.035 & 0.059 & 0.039 & 0.052 \\
$v \in(125,150]$ & 0.069 & 0.082 & 0.042 & 0.076 \\
\hline
\end{tabular}

Table 5: Median degree of bid shading in the second auction.

his second auction bid more than the losers. The finding that the efficiency does not decrease for an asymmetric first-price auction is therefore not caused by the absence of a distinction in bid shading by the two types of bidders. Compared to Güth et al. (2005), we find much lower shading which can be explained by the fact that we have four bidders of which three are of the unfavorable type. The differences in shading of winners and losers are small and, therefore, as well the probability of an inefficient auction caused by this difference.

In this subsection we discussed the efficiency results. We observed that in the first auction of a round, the average efficiency within a pricing rule decreases in the synergy factor. When positive synergies are present, the efficiency is lower in the second-price auctions than in the first-price auctions, although this difference is only significant in a comparison between FP2.0 and SP2.0. For the second auction of a round, we do not observe any significant decrease in efficiency within either of the two pricing rules. Surprisingly, the efficiency in the asymmetric first-price auction is not lower than that in a second-price auction for the same positive synergy factor. A possible explanation for this is that the difference in bid-shading of a first auction winner and loser is rather small.

\subsection{Revenue}

The seller's revenue consists of the prices received in each auction of a round. In Table 6, the average prices in the first and second auction are presented and compared for a given synergy factor. In the last two rows of the table, the same is done for the revenue. The exact two-sided Mann-Whitney statistics are based on average prices per group.

\begin{tabular}{|c|c|c|c|}
\hline & FP1.0 & FP1.5 & FP2.0 \\
\hline Price 1 & 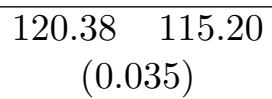 & 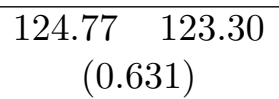 & $\begin{array}{c}131.90 \quad 132.41 \\
(1.000)\end{array}$ \\
\hline Price 2 & $\begin{array}{c}119.16 \quad 113.32 \\
(0.015)\end{array}$ & $\begin{array}{c}128.84 \quad 119.24 \\
(0.000)\end{array}$ & $\begin{array}{c}137.75 \quad 127.74 \\
(0.002)\end{array}$ \\
\hline Revenue & $\begin{array}{c}239.53 \quad 228.51 \\
(0.003)\end{array}$ & $\begin{array}{c}253.61 \quad 242.54 \\
(0.000)\end{array}$ & $\begin{array}{c}269.66 \quad 260.15 \\
(0.105)\end{array}$ \\
\hline
\end{tabular}

Table 6: The average price of each auction in a round and the revenue for all treatments. In brackets are the exact two-sided Mann-Whitney statistics, which are based on the averages per group. 
Within both the first- and second-price treatments, average prices significantly increase in the synergy factor. ${ }^{5}$ The underlying forces at work are similar for both pricing formats. Namely, in the first auction, the option value effect increases in the synergy factor. In the second auction, the valuation of one of the four bidders increases (in expectation).

For both the first and second auction, a comparison between average prices in FP1.0 and SP1.0 shows that prices are significantly higher in the first-price auctions. Although it opposes to the revenue-equivalence theorem, this is a common experimental finding.

When positive synergies are present, the prices in the first auction of a round do not differ significantly, for a given synergy factor, between the first- and second-price treatments. The increase in the average price for the different synergy factors is larger in the second-price treatments. This suggests that bidders value the option value more in a second-price auction than in a first-price auction.

The prices in the second auction of a round are significantly higher in the first-price auction for a given synergy factor. Maskin and Riley (2000) showed that with this kind of asymmetry, indeed the expected revenue from a first-price auction is higher than from a second-price auction. It appears then that this finding also holds experimentally for four bidders.

Average revenue in FP2.0 is not significantly higher than in SP2.0. We already observed that average prices do not differ in the first auction and that average prices in FP2.0 are higher in the second auction. Still, the overall effect on revenue is indeterminate. When comparing first auction prices in FP1.5 and SP1.5 we also do not find a significant difference, but total revenue in FP1.5 is significantly higher.

There has been a lot of interest in price trends in sequential auctions. Weber (1983) shows that if bidders demand a single unit, the prices in a sequential auction of identical objects are a martingale; that is, in expectation prices drift neither up nor down. However, there is ample empirical evidence of declining price trends in sequential auctions, which is known as the declining price anomaly or afternoon effect. For instance, declining prices are observed in wine auctions (Ashenfelter, 1989, and McAfee and Vincent, 1993), real estate auctions (Ashenfelter and Genesove, 1992), and impressionist and modern paintings auctions (Beggs and Graddy, 1997). Declining prices have also been observed in experimental settings (Burns, 1985, Keser and Olson, 1996, and Neugebauer and Pezanis-Christou, 2007).

Jeitschko and Wolfstetter (2002) conclude that, in case of two bidders, the expected price in the second auction is below that in the first auction for both first- and second-price auctions. From the average prices in Table 6 , it can be seen that we indeed observe a higher average price in the first auction in SP1.5 and SP2.0. However, for both FP1.5 and FP2.0 the average price is lower in the first auction than in the second auction.

\footnotetext{
${ }^{5}$ One-sided Mann-Whitney tests show that all differences within pricing rules are significant. Price 1: FP1.0 <.018 FP1.5<.001 FP2.0 and SP1.0<.003 SP1.5<.014 SP2.0

Price $2:$ FP1.0 $<.000$ FP1.5 <.000 FP2.0 and SP1.0<.003 SP1.5<.000 SP2.0
} 


\begin{tabular}{lcccccc}
\hline & FP1.0 & SP1.0 & FP1.5 & SP1.5 & FP2.0 & SP2.0 \\
\hline Declining & 1 & 1 & 0 & 3 & 0 & 2 \\
No difference & 9 & 9 & 7 & 7 & 6 & 8 \\
Increasing & 0 & 0 & 3 & 0 & 4 & 0 \\
\hline
\end{tabular}

Table 7: Price trends over the auctions within a round.

Within each independent observation, we analyze the price trend by comparing the prices in the first and second auction of a round using a one-sided Wilcoxon signed-rank test. Table 7 shows for each treatment the number of independent observations in which the prices significantly decline or increase within a round, at a significance level of five percent. The pricing format appears to influence the observed price trend when positive synergies are present. For both baseline treatments, we do not observe any difference between the price trends. However, once positive synergies are present, there are more observations with significantly declining prices in SP1.5 and SP2.0 and with significantly increasing prices in FP1.5 and FP2.0. Performing a sign-test or increasing the significance level to ten percent results in the same insight.

In this subsection, we discussed revenues and price trends. When positive synergies are present, the prices in the first auction of a round do not differ significantly between the firstand second-price treatments for given positive synergies. In contrast, the prices in the second auction of a round are always significantly higher in the first-price treatments. The overall revenue is also always higher in the first-price treatments, although this is not significant at five percent significance level for synergy factor 2.0. Finally, it appears that the presence of positive synergies gives rise to opposing price trends for both pricing-formats.

\subsection{Payoffs}

The average auction payoffs for a bidder are shown in Table 8. Within both the first- and second-price treatments, the first auction payoff decreases in the synergy factor whereas the second auction payoff increases in the synergy factor. ${ }^{6}$ In both FP2.0 and SP2.0, the average first auction payoff becomes even negative. In the bottom part of the table, we compare the average round payoffs between the two pricing formats for a given synergy factor.

The test results in the table are in line with what was previously observed for prices. For both the first and second auction, a comparison between average payoffs in FP1.0 and SP1.0 shows that payoffs are significantly lower in the first-price auctions. When positive synergies are present, the payoffs in the first auction of a round do not differ significantly for a given synergy factor. The payoffs in the second auction are significantly lower in the first-price auction for a given synergy factor. Finally, note that the difference in average round payoff

\footnotetext{
${ }^{6}$ One-sided Mann-Whitney tests show that all differences within pricing rules are significant. Payoff 1: FP1.0 <.007 FP1.5 <.001 FP2.0 and SP1.0<.000 SP1.5<.014 SP2.0 Payoff 2: FP1.0 >.004 FP1.5 >.000 FP2.0 and SP1.0 >.001 SP1.5>.004 SP2.0
} 


\begin{tabular}{lcccccc}
\hline & FP1.0 & SP1.0 & FP1.5 & SP1.5 & FP2.0 & SP2.0 \\
\hline Auction 1 & 2.33 & 3.63 & 1.17 & 1.14 & -0.74 & -1.39 \\
& $(0.003)$ & $(0.579)$ & \multicolumn{2}{c}{$(0.393)$} \\
Auction 2 & 2.58 & 4.08 & 3.73 & 6.58 & 5.96 & 8.69 \\
\multirow{4}{*}{ Round } & $(0.004)$ & $(0.002)$ & \multicolumn{2}{c}{$(0.000)$} \\
& 4.91 & 7.71 & 4.90 & 7.73 & 5.22 & 7.30 \\
& $(0.001)$ & $(0.015)$ & $(0.089)$ \\
\hline
\end{tabular}

Table 8: The average payoff in ECU per auction for each treatment. The exact two-sided MannWhitney statistics are given between brackets and based on average payoffs per group.

is smaller between FP2.0 and SP2.0 than between FP1.0 and SP1.0.

Although the possible surplus that can be divided between bidders and seller increases in the synergy factor, we showed in Section 2 that the expected round payoff decreases in the synergy factor. Within both the first- and second-price treatments, the realized average round payoff remains approximately the same when the synergy factor increases. For the second-price treatments, the average round payoff is even lowest in SP2.0. Comparing the payoffs between treatments with the same pricing rule using a one-sided Mann-Whitney test based on average round payoffs per group never leads to the rejection of equality. ${ }^{7}$ Thus, subjects do not bid aggressive enough to suffer from the presence of positive synergies. Still, the seller always reaps the increase in surplus that is due to the positive synergies.

In the first auction of a round, subjects do not only bid for the object but also to be the strong bidder in the second auction. In Table 9, we show the average second auction payoff for a bidder, depending on whether he won or lost the first auction of a round. The option value of winning the first auction is then the difference between the payoffs of both types.

\begin{tabular}{lccrrrr}
\hline & FP1.0 & SP1.0 & FP1.5 & SP1.5 & FP2.0 & SP2.0 \\
\hline Winner & 2.70 & 4.47 & 10.62 & 19.51 & 21.95 & 31.00 \\
Loser & 2.54 & 3.94 & 1.43 & 2.27 & 0.64 & 1.25 \\
Option value & 0.16 & 0.53 & 9.20 & 17.24 & 21.31 & 29.75 \\
& $(0.986)$ & $(0.003)$ & \multicolumn{2}{c}{$(0.000)$}
\end{tabular}

Table 9: The average second auction payoff for the winner and a loser of the first auction in a round. The exact two-sided Mann-Whitney statistics are given between brackets and based on average payoffs per group.

Given the synergy factor, the average second auction payoffs are lowest for both types in the first-price treatments. When positive synergies are present, the payoff of the winner increases in the synergy factor, whereas that of the loser decreases. Consequently, the option value increases in the synergy factor. Based on a two-sided Wilcoxon signed-rank test on the average option value per independent observation, we cannot reject that the option value

\footnotetext{
${ }^{7} \mathrm{FP} 1.0 \sim .434 \mathrm{FP} 1.5, \mathrm{FP} 1.0 \sim .485 \mathrm{FP} 2.0, \mathrm{FP} 1.5 \sim .485 \mathrm{FP} 2.0$, $\mathrm{SP} 1.0 \sim .485 \mathrm{SP} 1.5, \mathrm{SP} 1.0 \sim .427 \mathrm{SP} 2.0, \mathrm{SP} 1.5 \sim .427$ SP2.0
} 
equals zero in both FP1.0 $(p=0.770)$ and SP1.0 $(p=1.000)$. As can be seen in Table 9 , the option value is always significantly larger in the second-price treatment for a given positive synergy factor.

The larger the option value, the higher bidders should bid for it. For the first auction of a round, the larger option value then explains the more rapid decrease of payoffs in the second-price treatments. Without positive synergies, the option value is zero and we observe significantly higher payoffs in the second-price treatments. When positive synergies are present, the option value is higher in the second-price treatment, and, as a consequence, the payoff difference between the two pricing formats disappears. The same reasoning applies for the first auction prices.

In this auction setting, bidders face an exposure problem as they can end up winning one object that is too expensive if the second object is not also won. We already observed that average first auction payoffs decrease in the synergy factor and even become negative. In order to analyze the consequences of the exposure problem, we count the number of times a bidder receives a negative payoff from a round. We only count round losses that are caused by a loss made in the first auction of a round. This measure excludes round losses that are caused by the second auction in a round, since such losses are not stemming from the presence of positive synergies. ${ }^{8}$ In Table 10, the average and relative number of round losses are listed per treatment. The one-sided Mann-Whitney statistics are based on the number of round losses per independent observation.

\begin{tabular}{lcrrrrr}
\hline & FP1.0 & SP1.0 & FP1.5 & SP1.5 & FP2.0 & SP2.0 \\
\hline Average & 0.30 & 3.40 & 2.30 & 5.90 & 6.10 & 7.50 \\
Percentage & 1.20 & 13.60 & 9.20 & 23.60 & 24.40 & 30.00 \\
& $(0.000)$ & $(0.006)$ & $(0.171)$ \\
\hline
\end{tabular}

Table 10: The average and relative number of round losses for each treatment. Mann-Whitney statistics are given between brackets

The average number of round losses is always larger in the second-price treatments. In SP1.0 and FP1.0, losses can only be caused by irrational bidding behavior. As is often observed in experiments, bidding above valuation occurs in the second-price auction but not in the first-price auction.

When positive synergies are present, the option value makes the value of winning the first auction higher than just the bidder's valuation for the object. For a second-price auction this immediately implies that it is optimal to bid above one's valuation for the object. In a standard first-price auction, bidders shade their bids, and therefore, the presence of the option value does not immediately imply bidding above one's valuation. Leufkens and Peeters (2007) show, for two bidders, that the number of round losses tends to be lower in first-price auctions, but that the difference almost vanishes when the synergy factor becomes large.

\footnotetext{
${ }^{8}$ Our findings are robust to counting all negative round payoffs.
} 
When comparing FP1.5 with SP1.5 we observe a significant negative difference that is larger than between the baseline treatments. For synergy factor 2.0, there is no significant difference between the number of round losses. It is interesting to note that given that a loss was made, the average loss was 14.43 in FP2.0 and 21.84 in SP2.0.

In this subsection we discussed the payoffs of subjects. We clearly observe differences in the average second auction payoff for the winner and the loser of the first auction. The option value is always significantly larger in the second-price treatments. The presence of a positive option value leads to more aggressive bidding in the first auction of a round. Consequently, the average first auction payoff decreases in the synergy factor and is even negative for large synergies. Still, the average earnings per subject over a round remain approximately constant within a pricing rule for the different sizes of the synergy factor. The occurrence of losses increases in the synergy factor, and with the exception of synergy factor 2.0 , is always significantly smaller in the first-price auction.

\section{Conclusion}

Winning multiple contracts in multi-unit auctions can lead to cost advantages due to synergies. In recurrent procurement auctions, the presence of synergies leads to an exposure problem and asymmetries among bidders. We consider sequential first- and second-price auctions in which winning the first auction leads to an increase in the valuation of the second object. In a series of experiments, we compare the performance of the two auction formats for three different sizes of the synergy.

We find that subjects indeed respond to the incentives provided by the presence of positive synergies. The average second auction payoff of a first auction winner is much larger than that of a first auction loser when positive synergies are present. The first auction is then not only about winning the first object, but also about increasing the expected second auction payoff. Consequently, the presence of a positive option value leads to more aggressive bidding in the first auction. The average first auction payoff decreases in the synergy factor and is even negative for large synergies.

Bidders face an exposure problem, since an instantaneous loss in the first auction might not be recovered during the second auction. For subjects, the faced exposure problem differs between the two pricing formats. In a second-price auction, bidders bid above their valuation as soon as the option value is positive, which can, but does not necessarily, lead to an instantaneous loss when the first object is won. In a first-price auction, bidders bid above their valuation if the option value is sufficiently large to offset the bid-shading. Then, winning the auction always results in an instantaneous loss. Furthermore, for a given positive synergy factor, the option value is always significantly larger in the second-price treatments. Both factors explain why the first auction bidding increases more in the synergy factor for the second-price treatments. However, the average earning of a subject remains approximately 
constant within a pricing rule, which contrasts the theoretical prediction. The occurrence of losses increases in the synergy factor, and with the exception of synergy factor 2.0, is always significantly smaller in the first-price auction.

When positive synergies are present, the prices in the first auction do not differ significantly between the first- and second-price treatments for given positive synergies. In contrast, the prices in the second auction are always significantly higher in the first-price treatments. The overall revenue is also always higher in the first-price treatments, although this is not significant at five percent significance level for synergy factor 2.0. Finally, it appears that the presence of positive synergies gives rise to opposing price trends for both pricing-formats. Within the first-price treatments, we observe an increase in the number of observations with an increasing price trend, whereas within the second-price treatments we observe an increase in the number of observations with a declining price trend.

We observe that in the first auction, the average efficiency within a pricing rule decreases in the synergy factor. When positive synergies are present, the efficiency is lower in the secondprice auctions than in the first-price auctions, although this difference is only significant for a comparison with synergy factor 2.0. For the second auction, we do not observe any significant decrease in efficiency within either of the two pricing rules. Surprisingly, the efficiency in the asymmetric first-price auction is not lower than that in the second-price auction for the same positive synergy factor. A possible explanation for this is that the difference in bid-shading of a first auction winner and loser is rather small.

For small synergies, the first-price auction performs better in terms of efficiency, revenue and the probability on losses. Once the synergy factor becomes very large, the performance of the two different pricing formats becomes more similar, although the first-price auction never performs worse than the second-price auction on all three aspects. Our results provide support for the common use of first-price rather than second-price auctions when the exposure problem is present, in particular for recurrent procurement settings.

\section{References}

1. Ashenfelter, O. (1989). How auctions work for wine and art. Journal of Economic Perspectives, 3 (3), 23-36.

2. Ashenfelter, O. and D. Genesove (1992). Testing for price anomalies in real-estate auctions. American Economic Review, 82 (2), 501-505.

3. Ausubel, L., P. Cramton, R.P. McAfee, and J. McMillan (1997). Synergies in wireless telephony: Evidence from the broadband PCS auctions. Journal of Economics and Management Strategy, 6 (3), 497-527.

4. Beggs, A. and K. Graddy (1997). Declining values and the afternoon effect: Evidence from art auctions. RAND Journal of Economics, 28 (3), 544-565. 
5. Branco, F. (1997). Sequential auctions with synergies: An example. Economics Letters, 54 (2), 159-163.

6. Burns, P. (1985). Experience and decision-making: A comparison of students and businessmen in a simulated progressive auction. Research in Experimental Economics III, 139-157.

7. Cramton, P. (2002). Spectrum auctions. In: Cave, M., S. Majumdar, and I. Vogelsang, Handbook of telecommunications economics. Amsterdam: Elsevier, pp. 605-639.

8. De Silva, D.G. (2005). Synergies in recurring procurement auctions: An empirical investigation. Economic Inquiry, 43 (1), 55-66.

9. De Silva, D.G., T.D. Jeitschko, and G. Kosmopoulou (2005). Stochastic synergies in sequential auctions. International Journal of Industrial Organization, 23 (3-4), 183-201.

10. Février, P., L. Linnemer, and M. Visser (2007). Buy or wait, that is the option: The buyer's option in sequential laboratory auctions. RAND Journal of Economics, 38 (1), 98-118.

11. Fischbacher, U. (2007). z-Tree: Zurich Toolbox for Ready-made Economic Experiments. Experimental Economics, 10 (2), 171-178.

12. Grimm, V., F. Mengel, L. Viianto, and G. Ponti (2006). Investment Incentives in Procurement Auctions: An Experiment. Working Paper.

13. Güth, W., R. Ivanova-Stenzel, and E. Wolfstetter. (2005). Bidding behavior in asymmetric auctions: An experimental study. European Economic Review, 49 (7), 1891-1913.

14. Hendricks, K. and R. Porter (1988). An empirical study of an auctions with asymmetric information. The American Economic Review, 78 (5), 865-883.

15. Huck, S., H.T. Norman, and J. Oechssler (2004). Two are few and four are many: Number effects in experimental oligopoly. Journal of Economic Behavior and Organization, $53(4), 435-446$.

16. Jeitschko, T.D. and E. Wolfstetter (2002). Scale economies and the dynamics of recurring auctions. Economic Inquiry, 40 (3), 403-414.

17. Keser, C. and M. Olson (1996). Experimental examination of the declining price anomaly. In: Ginsburgh, V. and P.M. Menger, Economics of the arts: Selected essays. Amsterdam: Elsevier, pp. 151-175.

18. Lebrun, B. (1998). Comparative statics in first-price auctions. Games and Economic Behavior, 25 (1), 97-110. 
19. Leufkens, K., R. Peeters, and D. Vermeulen (2006). Sequential auctions with synergies: The paradox of positive synergies. METEOR Research Memorandum 06/018, Universiteit Maastricht, pp. 1-19.

20. Leufkens, K. and R. Peeters (2007). Synergies are a reason to prefer first-price auctions. Economics Letters, 97 (1) 64-69.

21. Maskin, E. and J. Riley (2000). Asymmetric auctions. Review of Economic Studies, 67 (3), 413-438.

22. McAfee, R.P. and D. Vincent (1993). The declining price anomaly. Journal of Economic Theory, 60 (1), 191-212.

23. Neugebauer, T. and P. Pezanis-Christou (2007). Bidding behavior at sequential firstprice auctions with(out) supply uncertainty: A laboratory analysis. Journal of Economic Behavior and Organization, 63 (1), 55-72.

24. Plum, M. (1992). Characterization and computation of Nash-equilibria for auctions with incomplete Information. International Journal of Game Theory, 20 (4), 393-418.

25. Rusco, F. and D. Walls (1999). Competition in a repeated spatial auction market with an application to timber sales. Journal of Regional Science, 39 (3), 449-465.

26. Van Damme, E. (2002). The European UMTS-Auctions. European Economic Review, 46 (4-5), 846-869.

27. Weber, R.J. (1983). Multiple-objects auctions. In: Engelbrecht-Wiggans, R., M. Shubik, and R.M. Stark, Auctions, bidding and contracting: Uses and theory. New York: New York University Press, pp. 165-194. 


\section{Appendix}

\section{A Instructions}

We provide the instructions of treatment FP1.5 here. Instructions of other treatments can be obtained from the authors on request.

Dear participant, welcome to this experiment. This experiment will last about 1.5 hours and you will be compensated according to your performance. In order to ensure that the experiment takes place in an optimal setting, we would like to ask you to follow the general rules during the whole experiment:

- Read these instructions carefully! It is important that you understand the rules of this experiment. These instructions are identical for all students that participate together with you. If something is not explained well, please raise your hand. Do not ask the question out loud, but wait until one of the experimenters approaches you to answer the question privately.

- Switch off your mobile phone!

- Do not communicate with your fellow students! Even though the experiment may get exiting at times, it is very important that you remain silent through the proceedings.

- Focus on your own computer screen and not on other participants!

- There is paper and a pen on your table, which you can use during the experiment.

- After the experiment, please remain seated until you are paid off.

- If you do not obey the rules, the data becomes useless for us. Therefore we will have to exclude you from this experiment and you will not receive any compensation.

Your decisions and earnings in this experiment will remain anonymous.

General set-up In this experiment all of you are buyers of a fictitious object that is auctioned off. You can earn ECU (Experimental Currency Units) which will be exchanged into Euros at the end of the experiment. The exchange rate will be given in the instructions below. If you win an auction you do not receive the object but you receive an amount of ECU equal to your value of the object $v$. In return you have to pay the price $p$ resulting from the auction. Thus you receive a payoff of $v-p$ ECU. The rules of the auction will be discussed below. Before the experiment starts, you will be randomly divided into groups of 4 potential buyers. You will not know the identity of the 3 potential buyers you are matched with. The groups remain unchanged throughout the whole experiment. 
This experiment consists of 50 rounds. Each round consists of 2 auctions which are held after each other. Now we will explain the procedures in each round.

Auction rules In each auction you and the 3 other potential buyers in your group will be bidding for a single object that is auctioned off. In each auction the following happens. First you observe your value of the object. Then all of you are asked to submit a bid. Your bid can be any nonnegative number below 1000 .

Within each group, the winner is the subject who submitted the highest bid. The price the winner has to pay equals his bid. The payoff to the winner will be the difference between his value $v$ and the price he has to pay $p$. The payoff to the winner is thus given by the difference between his value and his bid. All other subjects get a payoff of 0 . In case the highest bid was submitted by more than one subject, the computer will randomly select a winner among those subjects.

Auction 1 Each round consists of two auctions and the proceedings in the first auction of each round are as follows.

First the value of the object will be determined for each subject. This value will be $v_{1}=50+x_{1}$ where $x_{1}$ is a randomly determined integer between 0 and 100 with each number being equally likely. Notice that $x_{1}$ is determined independently for each subject. Consequently the value of the object, $v_{1}$, will be a number between 50 and 150 for each bidder.

After observing your value, all of you are asked to submit a bid. Thus you will submit this bid after observing your value of the object but without observing the values or bids of the other subjects. To submit a bid you can fill in a number in the box and click on submit. Notice that your bid is not restricted to the interval $[50,150]$ but can be any nonnegative number below 1000 .

The bidding procedure in the first auction is illustrated in Figure 1 below. Note that the numbers are omitted in the illustration. 


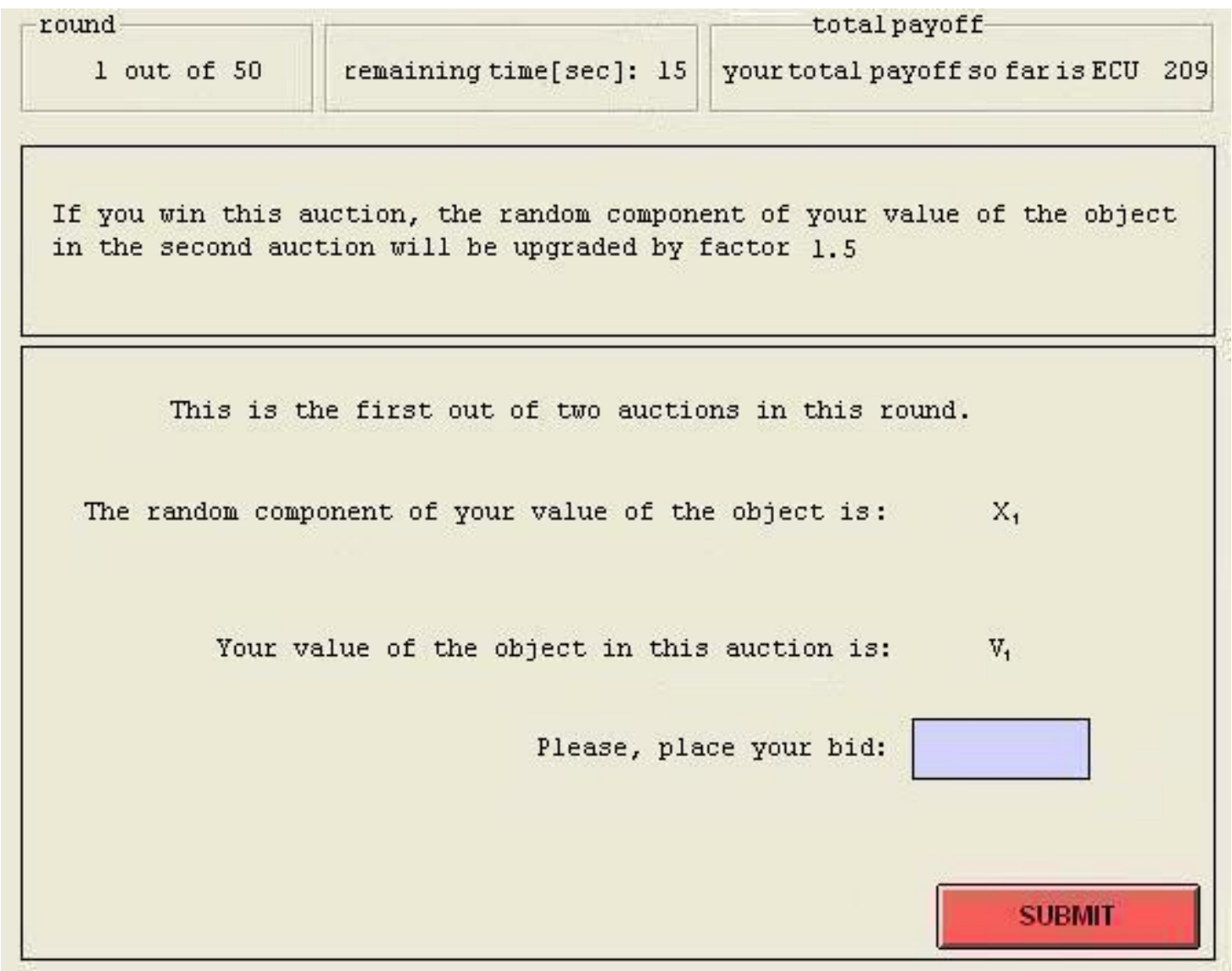

Figure 1: illustration of bidding in auction 1. On your screen you can see how your value of the object was constructed. The random component of your value is $x_{1}$ and consequently your value of the object in the first auction is $v_{1}$. To make a bid you can enter a number in the corresponding box and click on submit. The screen also shows that this is the first out of 50 rounds and that your total payoff so far is 209 .

The meaning of the sentence 'If you win this auction, the random component of your value of the object in the second auction will be upgraded by factor 1.5' will be clarified below.

After all of you submitted a bid, the winner and the price will be determined according to the rules mentioned above. The feedback on the result of the auction that will then appear on your screen is illustrated in Figure 2. Click on continue when you are ready for the second auction of this round. 


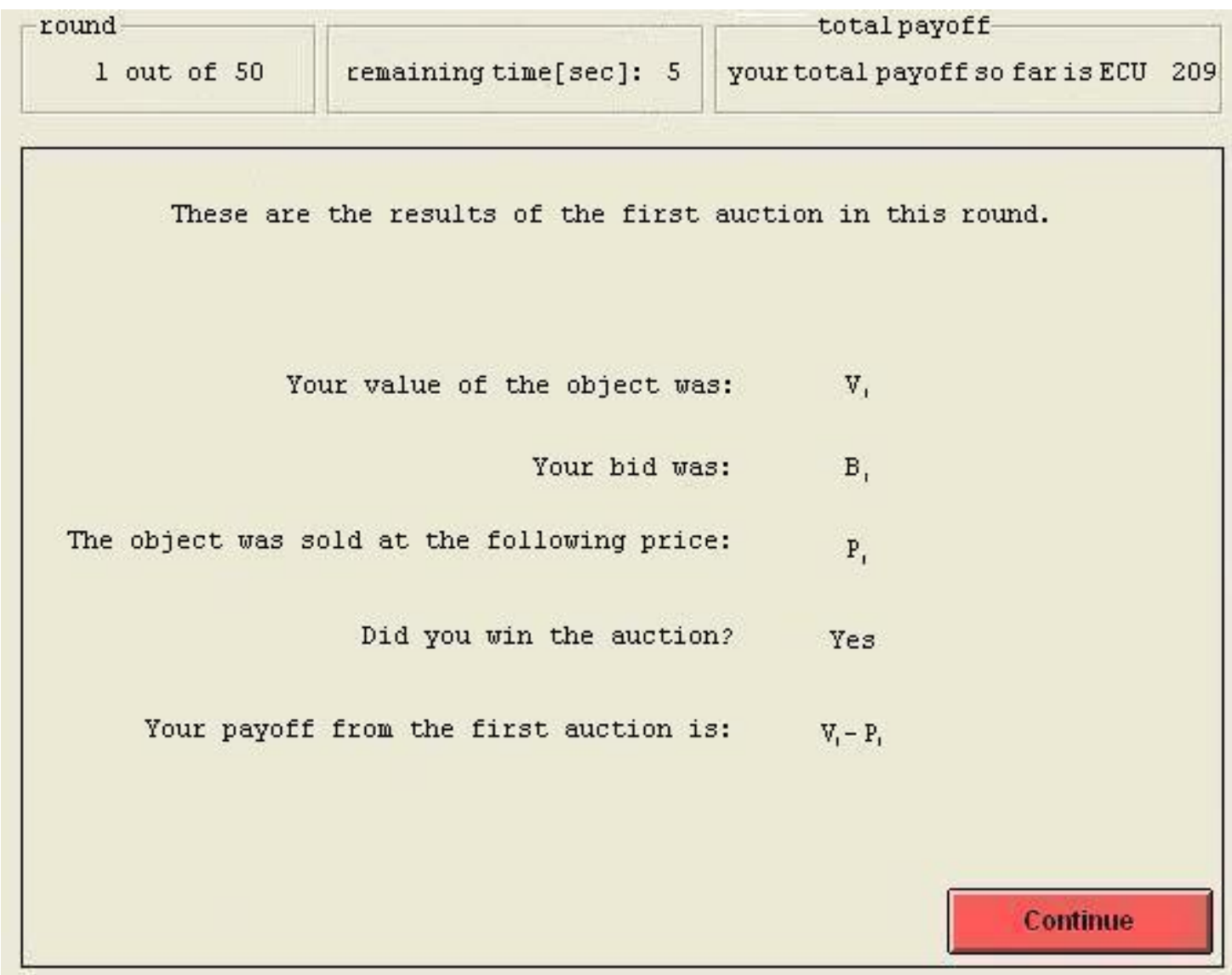

Figure 2: illustration of the results of auction 1 . Your value was $v_{1}$ and your bid was $b_{1}$. You won the auction and the price you have to pay is $p_{1}$ (which hence equals $b_{1}$ ). Consequently your payoff from the first auction in this round is the difference between your value and the price, namely $v_{1}-p_{1}$.

Auction 2 The proceedings in the second auction of each round are as follows.

A new value of the object will be determined for each subject. In case the first auction was not won, the value will be $v_{2}=50+x_{2}$ where, $x_{2}$ is a randomly determined integer between between 0 and 100 with each number being equally likely. In case the first auction was won, the value will be $v_{2}=50+1.5 \cdot x_{2}$ where, again, $x_{2}$ is a randomly determined integer between between 0 and 100 with each number being equally likely. Thus, for the subject that won the first auction the random component of the value of the object is multiplied by 1.5. Notice that $x_{2}$ is determined independently for each subject.

Consequently, the values of the 3 subjects that did not win the first auction lie between 50 and 150 and the value of the subject that won the first auction lies between 50 and 200 . Again notice that your bid is not restricted to the interval $[50,150]$ or $[50,200]$ but can be any nonnegative number below 1000 .

The bidding procedure in the second auction is illustrated in Figure 3 below. 


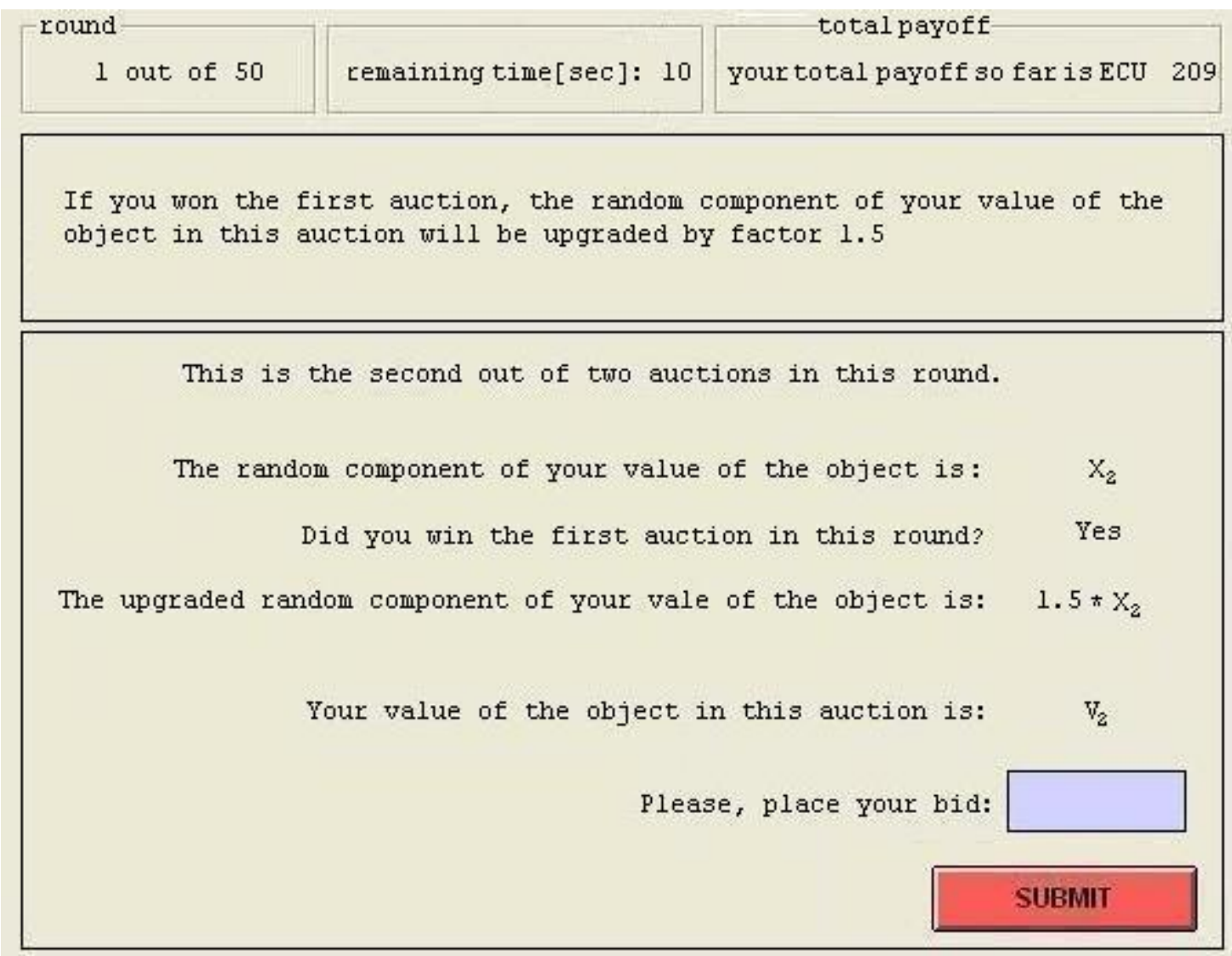

Figure 3: illustration of bidding in auction 2. On your screen you can see how your value of the object was constructed. Since you won the first auction, the random component of your value is multiplied by 1.5. Your value of the object after this upgrade is $v_{2}$. To make a bid you can enter a number in the corresponding box and click on submit.

In case the first auction was not won, the number that appears on your screen behind 'The upgraded random component of the object in this auction is:' is just a repetition of your random component of the value, since no upgrade takes place.

After all of you submitted a bid, the winner and the price will be determined according to the rules mentioned above. The feedback on the result of the auction and the round that will then appear on your screen is illustrated in Figure 4. 


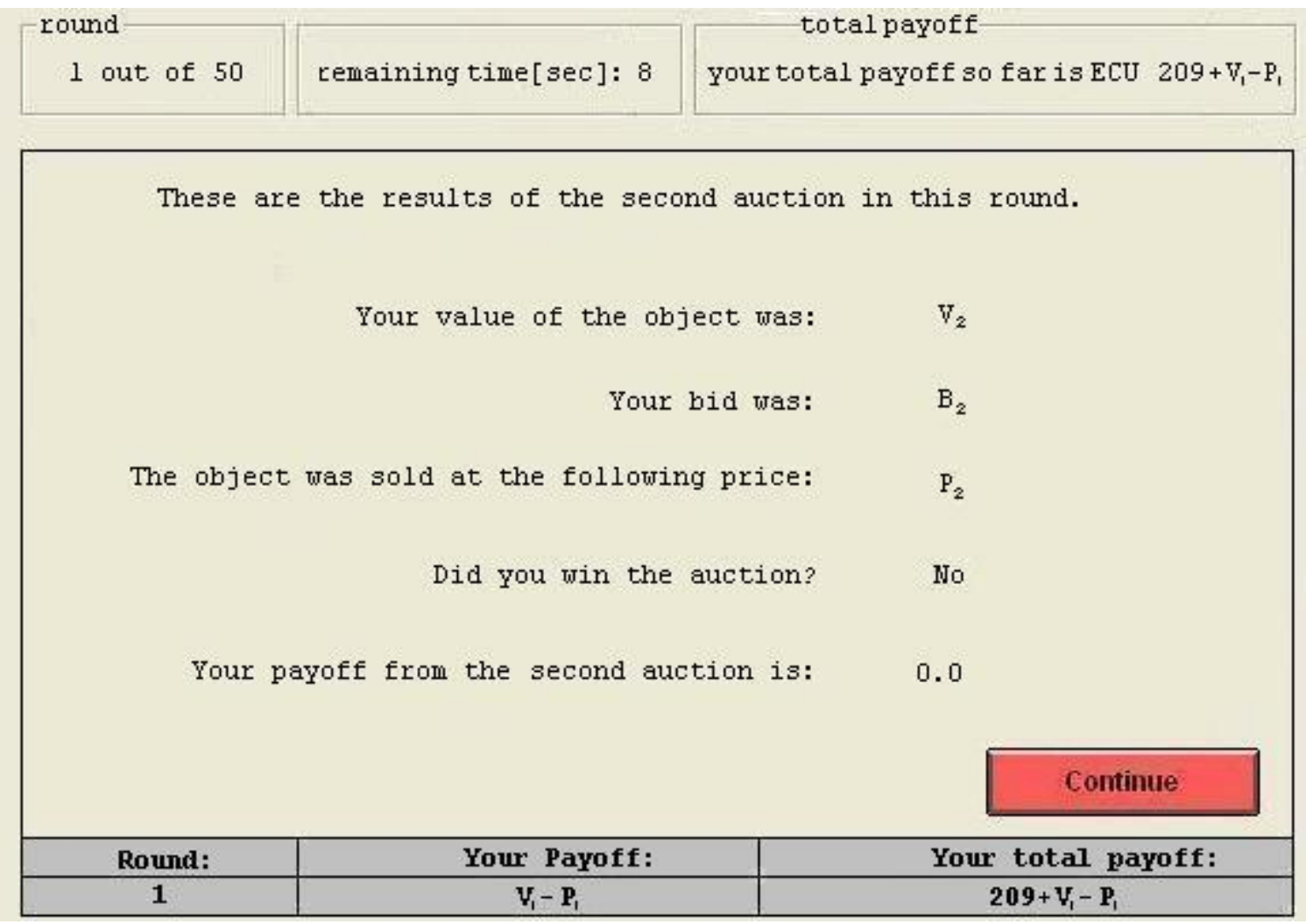

Figure 4: illustration of the results of auction 2. Your value of the object object was $v_{2}$. Your bid was $b_{2}$ and you did not win the auction. Consequently your payoff from the second auction in this round is zero. Your payoff from the round is the sum of the payoffs of both auctions and thus in this case $v_{1}-p_{1}$. This was the first round and therefore the total payoff in the upper right corner changes from 209 into $209+\left(v_{1}-p_{1}\right)$.

This ends the round and the first auction of a new round starts after all of you clicked Continue. In total you will participate in 50 rounds of 2 auctions each. After the last round of the experiment, we would like to ask you to complete a short questionnaire that will appear on your screen. Payments will be made by the experimenters afterwards.

ECU are transformed into Euros according to the following conversion rate: 1 ECU $=0.024$ Euro. You will get an initial endowment of 5 Euro (209 ECU).

Just like a profit is automatically added to your total payoff at the end of a round, a loss will be automatically deducted. If at the end of the experiment your total payoff is negative we will ask you to pay this amount of money to us. This situation is very unlikely to occur and under your control.

Before we start with the experiment we would like you to answer the questionnaire on the next page. One of the experimenters will go around and check the answers and discuss any problems. 


\section{Control questions}

Please answer the following questions. When you are finished, please raise your hand. One of the experimenters will come to you and check whether everything is correct.

1.) How many subjects are bidding in an auction (including yourself)?

2.) Suppose that in the first auction the random component of your value is 82 . What is your value in the first auction?

3.) Suppose that you have a value of 86 for the object in the first auction. What can you conclude about the values of the three other potential buyers?

_ Their value is for sure 86 .

_ Their values might be 86 and might be different from that but all lie between 50 and 150 for sure.

_ Their values lie between 50 and 150 and are for sure different from 86.

4.) Suppose the four participants A, B, C, D submitted the following bids: A submitted 101, B submitted 93, C submitted 74, and D submitted 137 . Who wins the auction?
$-\mathrm{A}$
$-\mathrm{B}$
$-\mathrm{C}$
$\mathrm{D}$

5.) What price does this subject have to pay?
$-101$
$-93$
$-74$ 137

6.) Suppose the random component of your value is 45 in the first auction. What can you conclude about the random component of your value in the second auction before upgrading?

_ The random component will be 45 for sure.

_ The random component might be 45 and might be different from that but lies between 0 and 100 for sure.

_ The random component lies between 0 and 100 and is different from 45 for sure. 
7a.) Suppose you did not win the first auction and the drawn random component of your value in the second auction is 80 . What is the upgraded random component of your value?

7b.) and what is your value in the second auction?

8a.) Suppose you won the first auction and the drawn random component of your value in the second auction is 80 . What is the upgraded random component of your value?

8b.) and what is your value in the second auction?

9.) Suppose you buy the object for a price of 100 . Your value of the object is 121 . What is your payoff from this auction?

10.) Suppose you buy the object for a price of 120 . Your value of the object is 101 . What is your payoff from this auction? 